\title{
Coenzyme Q10 and polycitic ovary syndrome: Systematic review
}

\author{
Fabíola Leite Gouveia, Roberto Fernandes costa and Telma Maria Araújo Moura Lemos* \\ Federal University of Rio Grande do Norte, Natal, Rio Grande do Norte, Brazil
}

\begin{abstract}
Polycystic ovarian syndrome (PCOS) is the most common endocrinopathy in the reproductive phase of women, with a prevalence ranging from $2.2 \%$ to $26 \%$. In addition to hormonal and reproductive changes, it is common in PCOS to have risk factors for cardiovascular disease. Coenzyme Q10 is a benzoquinone used in glucose and lipid metabolism, being deficient in cases of Metabolic Syndrome when untreated and in most endocrine pathologies. In addition, coenzyme Q10 plays an important role in eliminating free radicals and in inhibiting lipid and protein oxidation, with a powerful antioxidant action. The search included the databases PubMed, Lilacs and SciELO, independent of language and publication date until 2014 September, besides reviewing the references that included studies randomized controlled. Out of the 6 eligible articles, 3 were included in the studies were published between 1934 and 2018 . In total, 253 subjects participated in the included studies, with variability of 10 days to 12 months. From 3 studies 2 evaluated the effect of coenzyme q10 supplementation on glucose metabolism, lipid metabolism and expression of metabolic and inflammatory markers, and the other study on ovulation induction. After 12 weeks two studies evaluated the effect of supplementation on metabolic markers and beneficial effects on glucose metabolism, total cholesterol and LDL and a significant improvement in the expression of biochemical and inflammatory markers were observed, and the other study improved ovulation in these women. The results indicate that supplementation with coenzyme q10 in women with polycystic ovary syndrome is an excellent alternative to improve their metabolism.
\end{abstract}

\section{Introduction}

Polycystic Ovarian Syndrome (PCOS) is an endocrine, metabolic, reproductive and heterogeneous disorder, very common in young women, it is of unknown etiology and high phenotype variation, first described in the medical literature by Stein and Leventhal in 1935, when it was reported the relation among polycystic ovaries, amenorrhea, hirsutism and obesity [1-4]. Currently, it is believed that the appearance of PCOS is associated with factors of genetic origin, being characterized as an oligogenic disorder [5,6]. Genes involved in the insulin signaling pathway and / or biosynthesis and regulation of androgens, as well as the participation of various environmental factors, such as diet and lifestyle. However, as these interactions happen resulting in the pathological picture of the syndrome, they are still not fully clarified $[7,8]$.

In 1990 the National Institute of Health Conference was held, which sought the first standardization of the diagnostic criteria for this syndrome. Updated in 2004 by the publication of the Rotterdam Consensus by the European Society of Human Reproduction and Embryology / American Society of Reproductive Medicine (ESHRE/ ASRM) and by the Androgen Excess and PCOS Society (AES-PCOS) guidelines in 2006, it was suggested that the definition of PCOS should include at least two of the following three criteria: (a) oligo and / or anovulation, (b) clinical signs and / or biochemical hyperandrogenism and (c) polycystic ovaries on ultrasonography and exclusion of diseases related to endocrine disorders [9-11].

The main clinical manifestations of PCOS are mainly explained by hyperandrogenism, a term used to describe the clinical and / or biochemical signs resulting from the increase in the biological action of androgens in the body. It may also be associated with insulin resistance (IR) with compensatory hyperinsulinemia, elevated glucose levels, hypercholesterolemia, hypertension, obesity and metabolic syndrome. Women with PCOS are at increased risk of developing type 2 diabetes mellitus (DM2) and cardiovascular disease (CVD) [12-15]. The hirsutism, characterized by the increase in the amount of masculinized hair, together with the appearance of acne, seborrhea and alopecia form the most obvious phenotypic characteristics of PCOS [16,17]. Considering the factors related to PCOS such as hyperinsulinemia, glucose intolerance and insulin resistance, the latter being the cause of hyperglycemia, which in turn promotes the auto-oxidation of glucose forming the final products of advanced glycation (AGE) and forming also, reactive oxygen species (ROS). According to studies the ingestion of CoQ10 may improve insulin function through modulation of insulin receptors and adiponectin [18].

Coenzyme Q10, also known as Ubiquinone, is a benzoquinone liposoluble that has particular relevance in eukaryotes because it plays an important role in the elimination of free radicals and in the inhibition of lipid and protein oxidation. This compound protects more than any other lipid soluble antioxidant, such as lycopene, $\beta$-carotene and $\alpha$-tocopherol [19-21]. CoQ10 is synthesized intracellularly from 4-hydroxybenzoic acid (in turn derived from L-tyrosine), the isoprenoid chain part being obtained through acetylCoA, originating from the mevalonic acid pathway. It is a molecule that is present in

${ }^{\star}$ Correspondence to: Telma Maria Araújo Moura Lemos, Department of Clinical and Toxicological, Federal University of Rio Grande do Norte, General Cordeiro St. / Natal / RN N, Petrópolis CEP: 59010-180, Brazil, Tel: 55-84- 3342-9797; E-mail: telmaml@yahoo.com.br

Key words: coenzyme q10, polycistic syndrome, metabolism

Received: October 05, 2018; Accepted: October 16, 2018; Published: October 19,2018 
the internal mitochondrial membrane, however, it is also present in smaller quantities in the membrane of several other organelles, such as peroxisomes, endoplasmic reticulum or lysosomes [22]. The amount of CoQ10 in the body increases until the age of 20 years and then it decreases throughout life [23]. But its deficiency can be caused by insufficient feeding, impairment in biosynthesis, excessive use by the body, or any combination of the three [24].

The effects of CoQ10 supplementation in women with PCOS are being studied and have shown beneficial results on the markers of insulin metabolism through modulation of insulin and adiponectin receptors as well as an improvement in glycemic control and promoting an increase in triglyceride lipolysis. These mechanisms may suggest the importance of CoQ10 administration in glucose metabolism and lipid profile in women with PCOS [25-28].

In this sense, this systematic review aimed to investigate and describe the studies that have as primary outcome the effect of coenzyme Q10 supplementation in women with polycystic ovary syndrome at reproductive age.

\section{Methods}

\section{Eligibility criteria}

We included studies that analyzed the effect of coenzyme Q10 supplementation in women with polycystic ovary syndrome at reproductive age.

\section{Search strategy and study selection}

Randomized, non-randomized trials, comparative and case-control studies were considered for the systematic review. PUBMED, LILACS, and SCIELO were searched for articles published up to september 15, 2018, regardless of language or publication date. The terms used for the search and their variants were: PCOS, polycystic ovary syndrome, Coenzyme Q10, COQ10. References from the original articles found were also analyzed. Studies with the coenzyme Q10 in patients with PCOS were included. Diagnostic criteria were considered valid if they conformed to 2003 Rotterdam [9] or 1990 National Institutes of Health (NIH) criteria. Studies not containing adequate diagnosis information about PCOS or not excluding other causes of hyperandrogenism were ruled out. Case series or reports and reviews were also excluded.

\section{Quadro 1: syntax of the terms used in each database}

\section{PUBMED}

"Polycystic Ovary Syndrome"[Mesh]" or "Ovary Syndrome, Polycystic" or "Syndrome, Polycystic Ovary" or "Stein-Leventhal Syndrome" or "Stein Leventhal Syndrome" or "Syndrome, Stein-Leventhal" or "Sclerocystic Ovarian Degeneration" or "Ovarian Degeneration, Sclerocystic" or "Sclerocystic Ovary Syndrome" or "Polycystic Ovarian Syndrome" or "Ovarian Syndrome, Polycystic" or "Polycystic Ovary Syndrome 1" or "Sclerocystic Ovaries" or "Ovary, Sclerocystic" or "Sclerocystic Ovary" AND ""coenzyme Q10" [Supplementary Concept]" or "CoQ 10" or "CoQ10" or "ubidecarenone" or "coenzymeQ10" or "ubiquinone Q10" or "Bio-Quinone Q10" or "2,3-dimethoxy-5-methyl6-decaprenylbenzoquinone" or "ubiquinone 50 " or "ubisemiquinone radical" or "Q-ter" or "ubisemiquinone" or "coenzyme Q10" or “(Z,Z,Z,Z,Z,Z,E,E,E)-isomer" or “coenzyme Q10, ion (1-), (all-E)-isomer

LILACS

"Polycystic Ovary Syndrome AND co-enzymeQ10"

SCIELO

"Ovary Syndrome, Polycystic AND co-enzymeQ10"

\section{Results}

In order to perform this systematic review, the search in the electronic databases resulted in 6 studies, of which three were discarded, one for studying repetition and one for studying pharmacological strategies in women with PCOS and the last one evaluated the effect of coenzyme Q10 in women in general.

After reading the article in full and applying the exclusion criteria, 3 studies remained in this systematic review (Figure 1). Of the studies included in this systematic review, 1 was a randomized study and two were randomized double blind studies [25-27]. The description of the studies, including the characteristics of the intervention and main findings, is presented in Table 1.

\section{Discussion}

Recent studies have focused on the use of coenzyme Q10 supplementation with the objective of improving the lipid, glucose, insulin, inflammatory and gene expression profiles of some markers in women with polycystic ovary syndrome. Refaeey et al. [25] in 2014 conducted a prospective randomized controlled study in which they assessed the effect of the combination of coenzyme Q10 and clomiphene citrate. The study included 110 women attending the Fertility Outpatient Clinic in Mansoura University Hospitals, Mansoura University, Egypt and a private practice setting in the period from January 2010 to January 2013. There were no statistically significant differences in age, parity, infertility time, BMI, signs and symptoms and in the hormonal profile. In the group that made the combination of coenzyme Q10 and clomiphene citrate a decrease in endometrial thickness was observed compared to the group that used only clomiphene citrate from $8.82 \pm$ 0.27 to $7.03 \pm 0.74 \mathrm{~mm} ; \mathrm{p}<0.001$, respectively. Serum concentrations of estradiol and progesterone were significantly increased when combined with coenzyme Q10 ( $\mathrm{p}<0.05$ and $\mathrm{p}<0.001$, respectively. Of the 82 women with PCOS who used coenzyme Q10, 54 of them ovulated (65.9\%) and $37.3 \%$ of the women became pregnant compared to the group that used only clomiphene citrate. When clomiphene citrate was used along with coenzyme Q10 it was better adjuvant for ovulatory agents, proving to be more effective, safer, with lower cost for follicular development before an invasive treatment was necessary. Coenzyme Q10 is a benzoquinone found in the pancreas, liver and other organs, which has particular relevance in eukaryotes because it plays an important role in the elimination of free radicals and in the inhibition of lipid and protein oxidation [15] and it is used by body cells in breathing processes and aerobic, oxidative or cellular respiration metabolism [29]. This study is the only one that shows the effect of coenzyme Q10 supplementation on female reproduction. We can highlight the impact of the action of the free radicals altering processes of replication, alteration in the signaling pathways contributing to genomic instability causing mutation and cellular death. The oocytes, which are cells that through meiotic divisions give rise to the egg that plays an important role in the process of fertilization and development of embryos, which, in turn, when mitochondrial dysfunction occurs, favors cell aging by decreasing mitochondrial energy and favoring thus oxidative stress [26]. The importance with coenzyme Q10 supplementation is that its action with a good liposoluble oxidant decreases this oxidative process within the ovary [30]. Samimi et al. [26] and co-workers in 2017 conducted a double-blind randomized study of 60 women with polycystic ovarian syndrome where one group used placebo only and the other group used coenzyme Q10. The average age, baseline weight, BMI and METs and final weight test were not significantly different between the two groups. After 12 weeks of intervention, alopecia and acne decreased $(38.5 \%$ vs. $5.9 \%, \mathrm{P}=0.02)$ and $(57.1 \%$ vs $9.1 \%, \mathrm{P}=0.02)$ after consumption of CoQ10 supplements compared to the placebo. After 12 weeks of intervention, compared to the placebo, those receiving CoQ10 supplements had decreased fasting plasma glucose $(-0.24 \pm 0.51$ vs. $+0.01 \pm 0.44 \mathrm{mmol} / 1, \mathrm{P}=0.04)$, serum 


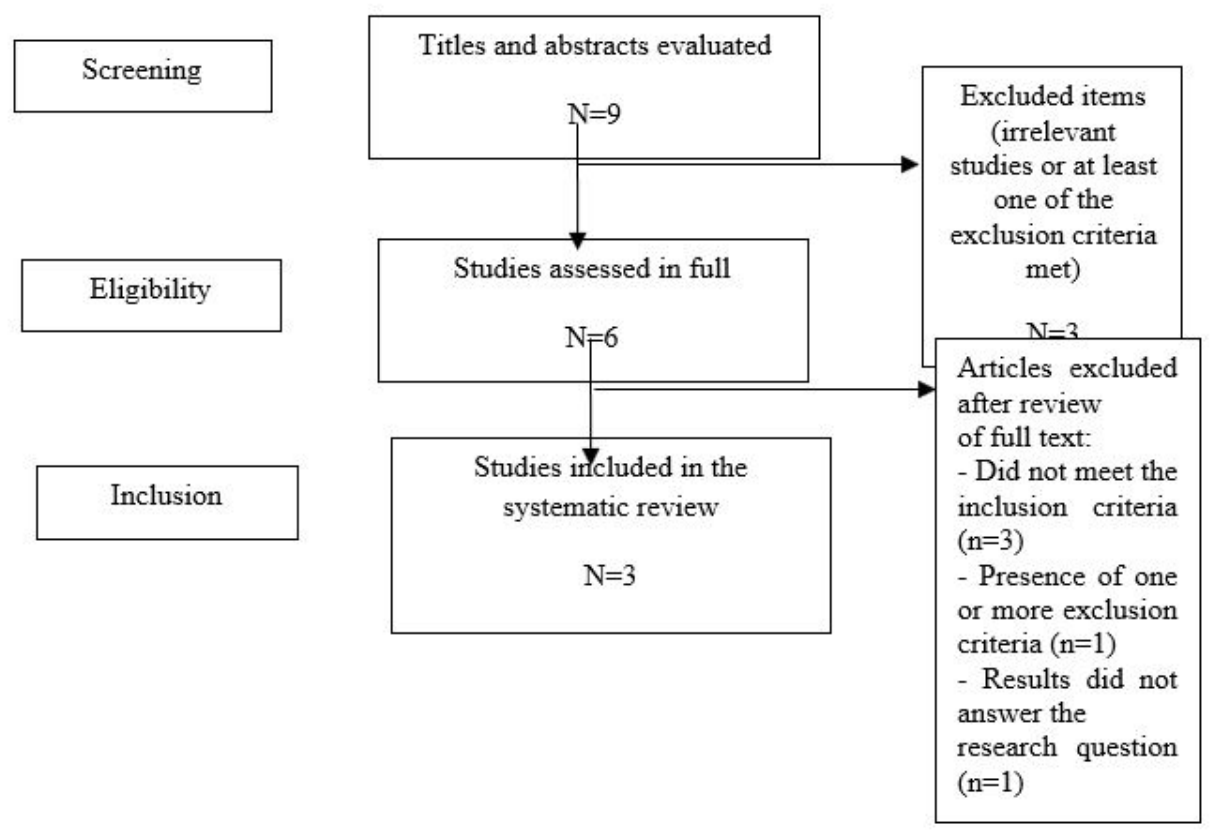

Figure 1. Flowchart of the process of sorting and selection of articles for inclusion in the review

Table 1. Characteristics of studies included in the review

\begin{tabular}{|c|c|c|c|c|c|c|c|c|}
\hline \multirow{2}{*}{ Study } & \multirow{2}{*}{$\begin{array}{c}\text { Diagnostic } \\
\text { Criteria of PCOS }\end{array}$} & \multirow{2}{*}{ Country } & \multirow{2}{*}{ Type of study } & \multirow{2}{*}{ Cases } & \multirow{2}{*}{ Controls } & Dosage & \multirow{2}{*}{ Time study } & \multirow{2}{*}{ Outcomes } \\
\hline & & & & & & CoQ10 & & \\
\hline \multirow[b]{2}{*}{$\begin{array}{c}\text { Refaeey, et al. } \\
2014\end{array}$} & 2003 Rotterdam & \multirow[b]{2}{*}{ Egypt } & \multirow[b]{2}{*}{ Randomized } & \multirow[b]{2}{*}{82} & \multirow[b]{2}{*}{71} & \multirow[b]{2}{*}{$150 \mathrm{mg} / \mathrm{dia}$} & \multirow[b]{2}{*}{$\begin{array}{l}10 \text { days before } \\
\text { stimulation }\end{array}$} & \multirow[b]{2}{*}{$\begin{array}{c}\text { Coenzyme Q10 } \\
\text { is a promising } \\
\text { ovulatory agent } \\
\text { when combined } \\
\text { with Clomiphene } \\
\text { Citrate }\end{array}$} \\
\hline & ESHRE/ASRM & & & & & & & \\
\hline \multirow[b]{2}{*}{$\begin{array}{c}\text { Rahmani, et al. } \\
2017\end{array}$} & 2003 Rotterdam & \multirow[b]{2}{*}{ Iran } & \multirow[b]{2}{*}{$\begin{array}{l}\text { Randomized } \\
\text { double blind }\end{array}$} & \multirow[b]{2}{*}{20} & \multirow[b]{2}{*}{20} & \multirow[b]{2}{*}{$20 \mathrm{mg} / \mathrm{kg}$} & \multirow[b]{2}{*}{12 weeks } & \multirow[b]{2}{*}{$\begin{array}{l}\text { Supplementation } \\
\text { significantly } \\
\text { increased the gene } \\
\text { expression of } \\
\text { LDLR, PPAR- } \gamma \text {, } \\
\text { IL-1, IL- } 8 \text { and } \\
\text { TNF- } \alpha\end{array}$} \\
\hline & ESHRE/ASRM & & & & & & & \\
\hline \multirow[b]{2}{*}{$\begin{array}{c}\text { Samimi, et al. } \\
2017\end{array}$} & 2003 Rotterdam & \multirow[b]{2}{*}{ Iran } & \multirow[b]{2}{*}{$\begin{array}{l}\text { Randomized } \\
\text { double blind }\end{array}$} & \multirow[b]{2}{*}{30} & \multirow[b]{2}{*}{30} & \multirow[b]{2}{*}{$100 \mathrm{mg}$} & \multirow[b]{2}{*}{12 weeks } & \multirow{2}{*}{$\begin{array}{l}\text { Supplementation } \\
\text { improves the } \\
\text { metabolism of } \\
\text { glucose, LDL } \\
\text { cholesterol }\end{array}$} \\
\hline & ESHRE/ASRM & & & & & & & \\
\hline
\end{tabular}

insulin concentrations $(-7.8 \pm(-0.3 \pm 0.6$ vs. $+0.2 \pm 0.6, \mathrm{P}=0.01)$, HOMA- $\beta(-5.4 \pm 9.5$ vs. $+4.5 \pm 9.9, \mathrm{P}<0.001)$ and increased QUICKI $(+0.006 \pm 0.009$ vs $-0.006 \pm 0.01, \mathrm{P}<0.001)$. In addition, changes in total cholesterol $(-0.10 \pm 0.48$ vs $+0.19 \pm 0.50 \mathrm{mmol} / \mathrm{l}, \mathrm{P}=0.02)$ and LDL cholesterol concentrations $(-0.15 \pm 0.40$ vs. $+0.14 \pm 0.49 \mathrm{mmol}$ $/ \mathrm{l}, \mathrm{P}=0.01)$ in women were significantly different from those in the placebo group. Rahmani et al. [27] in 2017 performed a study with 40 women where 20 of them received placebo and 20 were supplemented with Coenzyme Q10. There were no statistically significant variations in average age, height, weight and BMI. Women who used coenzyme Q10 showed a significant increase in the gene expression of LDLR ( $p$ $<0.001)$, PPAR- $\gamma,(\mathrm{p}=0.01), \mathrm{IL}-1(\mathrm{p}=0.03), \mathrm{IL}-8(\mathrm{p}=0.001$ and TNF- $\alpha$ $(\mathrm{p}<0.001)$. Ubiquinol which is a ubiquinin degradation product has an important role of regenerating vitamin $\mathrm{E}$ by protecting lipoprotein oxidation thereby lowering total cholesterol and LDL cholesterol concentrations thus preventing dyslipidemia and insulin by modulating insulin and adiponectin receptors, as well as tyrosine kinase (TK), phosphatidylinositol kinase (PI3K) and glucose transporters. Recent studies have shown that people with type 2 diabetes in hyperglycaemic conditions produce reactive oxygen species contributing to the malfunction of pancreatic beta cells by increasing glucose and insulin, but the mechanism is not well elucidated in women with polycystic ovary syndrome [31-33]. The Coenzyme Q10 has an important action on inflammatory processes in women with polycystic ovary syndrome. Low-grade chronic inflammation and imbalance between pro-and antiinflammatory cytokines play an important role in the pathogenesis of PCOS, such as the development of atherosclerosis and infertility [34]. Proinflammatory cytokines, such as tumor necrosis factor $\alpha$ (TNF- $\alpha$ ), interleukin 1A (IL-1A), IL-1B, IL-6, and IL-18 are the main mediators of inflammation $[35,36]$. Inflammation is associated with the activation of free radicals by inducing production of proinflammatory cytokines in Kupffer cells, thus increasing inflammation and apoptosis of liver cells. The close relation of the antioxidant action of coenzyme Q10 can inhibit the inflammatory cascade thus reducing inflammation. 


\section{Conclusion}

In the analysis of the studies included in this systematic review, the hormonal, biochemical, inflammatory and genetic parameters were improved when women with PCOS were supplemented with coenzyme Q10.

\section{Acknowledgements}

This study was supported by the Conselho Nacional de Desenvolvimento Científico e Tecnológico (CNPq), Ministério da Saúde do Brasil, and Fundação de Apoio à Pesquisa from the state of Rio Grande do Norte.

\section{Disclosure statement}

The authors have nothing to disclose.

\section{References}

1. Akbari M (2018) The effects of vitamin D supplementation on biomarkers of inflammation and oxidative stress among women with polycystic ovary syndrome: A systematic review and meta-analysis of randomized controlled trials. Horm Metab Res 50: 271-279.

2. Baskind NE, Balen AH (2005) Hypothalamic-pituitary, ovarian and adrenal contributions to polycystic ovary syndrome. Best Pract Res Clin Obstet Gynaecol 37: 80-97.

3. Fauser BC, Tarlatzis BC, Rebar RW (2012) Consensus on women's health aspects of polycystic ovary syndrome (PCOS): the Amsterdam ESHRE/ASRM-Sponsored 3rd PCOS Consensus Workshop Group. Fertil Steril 97: 28-38.

4. Stein IF, Leventhal ML (1935) Amenorrhea associated with bilateral polycystic ovaries. Am J Obstet Gynecol 29: 181-191.

5. Amato P, Simpson JL (2004) The genetics of polycystic ovary syndrome. Best Pract Res Clin Obstet Gynaecol 18: 707-718. [Crossref]

6. Escobar Morreale HF, Botella Carretero JI, Villuendas G (2004) Serum interleukin-18 concentrations are increased in the polycystic ovary syndrome: relationship to insulin resistance and to obesity. J Clin Endocrinol Metab 89: 806-811.

7. Xu X, Zhao H, Shi Y (2011) Family association study between INSR gene polymorphisms and PCOS in Han. Chinese Reproductive Biology and Endocrinology 9: 76 .

8. Goodarzi MO, Dumesic DA, Chazenbalk G, Azziz R (2011) Polycystic ovary syndrome: etiology, pathogenesis and diagnosis. Nat Rev Endocrinol 7: 219-231. [Crossref]

9. Goodarzi MO, Dumesic DA, Chazenbalk G, Azziz R (2011) Polycystic ovary syndrome: etiology, pathogenesis and diagnosis. Nat Rev Endocrinol 7: 219-231. [Crossref]

10. Rotterdam A (2004) Sponsored PCOS Consensus Workshop Group. Revised 2003 consensus on diagnostic criteria and long-term health risks related to polycystic ovary syndrome (PCOS). Hum Reprod 19: 41-47.

11. Azziz R, Woods KS, Reyna R, Key TJ, Knochenhauer ES, et al. (2004) The prevalence and features of the polycystic ovary syndrome in an unselected population. $J$ Clin Endocrinol Metab 89: 2745-2749. [Crossref]

12. Goodman N (2011) America Association of Clinical Endocrinologists medical guidelines for the clinical practice for the diagnosis and treatment of hiperandrogenic disordes. Endocr Pract 7: 120-134.

13. Azziz R, Carmina E, Dewailly D (2009) The Androgen Excess and PCOS Society criteria for the polycystic ovary syndrome: the complete task force report. Fertil and Steril 91: 456-488.

14. Moran LJ, Pasquali R, Teede HJ (2009) Treatment of obesity in polycystic ovary syndrome: a position statement of the Androgen Excess and Polycystic Ovary Syndrome Society. Fertil and Steril 92: 1966-1982.

15. Yildiz BO, Azziz RM (2010) Ovarian and adipose tissue dysfunction in polycystic ovary syndrome: report of the 4th special scientific meeting of the Androgen Excess and PCOS Society. Fertil and Steril 94: 690-693.

16. Jacewicz Swiecka M, Kowalska I (2018) Polycystic ovary syndrome and the risk of cardio-metabolic complications in longitudinal studies: a review of the data. Diabetes Metab Res 5: 1-10.
17. Yarak S, Bagatin E, Hassun KM (2005) Hiperandrogenismo e pele: síndrome do ovário policístico e resistência periférica a insulina. An Bras Dermatol 80: 395-410.

18. Romano LGM, Bedoschi G, Melo AS (2011) Anormalidades metabólicas em mulheres com síndrome dos ovários policísticos: obesas e não obesas. Rev Bras Ginecol Obstet 33: 310-316.

19. Amin MM, Asaad GF, Abdel Salam RM (2014) Novel CoQ10 antidiabetic mechanisms underlie its positive effect: modulation of insulin and adiponectine receptors, Tyrosine kinase, PI3K, glucose transporters, sRAGE and visfatin in insulin resistant/ diabetic rats. PLoS One 9: e89169.

20. Papucci L, Schiavone N, Witort E (2003) Coenzyme q10 prevents apoptosis by inhibiting mitochondrial depolarization independently of its free radical scavenging property. J Biol Chem 278: 28220-28228.

21. Bentinger M, Brismar K, Dallner G (2007) The antioxidant role of coenzyme Q Mitochondrion 7: 41-50. [Crossref]

22. Jafari M, Mousavi SM, Asgharzadeh A, Yazdani N (2018) Coenzyme Q10 in the treatment of heart failure: A systematic review of systematic reviews. Indian Heart $J$ 70: 111-117. [Crossref]

23. Bhagavan HN, Chopra RK (2006) Coenzyme Q10: absorption, tissue uptake, metabolism and pharmacokinetics. Free Radic Res 40: 445-453. [Crossref]

24. Turunen M, Olsson J, Dallner G (2004) Metabolism and function of coenzyme Q. Biochim Biophys Acta 1660: 171-199. [Crossref]

25. Littarru GP, Battino M, Tomasetti M, Mordente A, Santini S, et al. (1994) Metabolic implications of coenzyme Q10 in red blood cells and plasma lipoproteins. Mol Aspects Med 15: 67-72. [Crossref]

26. Refaeey AE, Selem A, Badawy A (2014) Combined coenzyme Q10 and clomiphene citrate for ovulation induction in clomiphene-citrate-resistant polycystic ovary syndrome. Reproductive BioMedicine Online, 29: 119-124.

27. Samimi M, Mehrizi MZ, Foroozanfard F (2017) The effects of coenzyme Q10 supplementation on glucose metabolism and lipid profiles in women with polycystic ovary syndrome: a randomized, double-blind, placebo-controlled. Clinical Endocrinology 86: 560-566.

28. Rahmani E, Jamilian M, Samimi M (2018) The effects of coenzyme Q10 supplementation on gene expression related to insulin, lipid and inflammation in patients with polycystic ovary syndrome. Gynecological Endocrinology 34: 217-222

29. Suksomboon N, Poolsup N, Juanak N (2015) Effects of coenzyme Q10 supplementation on metabolic profile in diabetes:a systematic review and meta-analysis. Journal of Clinical Pharmacy and Therapeutics, 40: 413-418.

30. West IC (2000) Radicals and oxidative stress in diabetes. Diabet Med 17: 171-180. [Crossref]

31. Özcan1 P, Fiçicioglu C, Kizilkale O (2016) Can Coenzyme Q10 supplementation protect the ovarian reserve against oxidative damage? Assist Reprod Genet 33: 12231230

32. Bonnefont Rousselot D, Bastard JP, Jaudon MC (2000) Consequences of the diabetic status on the oxidant/antioxidant balance. Diabetes Metab 26: 163-177.

33. West IC (2000) Radicals and oxidative stress in diabetes. Diabet Med 17: 171-180. [Crossref]

34. McCarty MF (1999) Can correction of sub-optimal coenzyme Q status improve betacell function in type II diabetics? Med Hypotheses 52: 397-400. [Crossref]

35. Venugopal SK, Devaraj S, Jialal I (2005) Effect of C-reactive protein on vascular cells: evidence for a proinflammatory, proatherogenic role. Curr Opin Nephrol Hypertens 14: 33-37.

36. Han KH, Hong KH, Park JH (2004) C-reactive protein promotes monocyte chemoattractant protein-1-mediated chemotaxis through upregulating CC chemokine receptor 2 expression in human monocytes. Circulation 109: 2566-2571.

Copyright: (C2018 Gouveia FL. This is an open-access article distributed under the terms of the Creative Commons Attribution License, which permits unrestricted use, distribution, and reproduction in any medium, provided the original author and source are credited. 